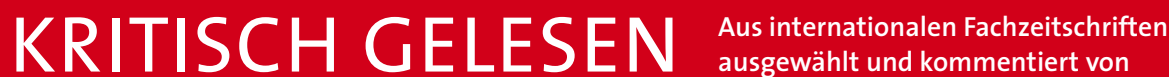

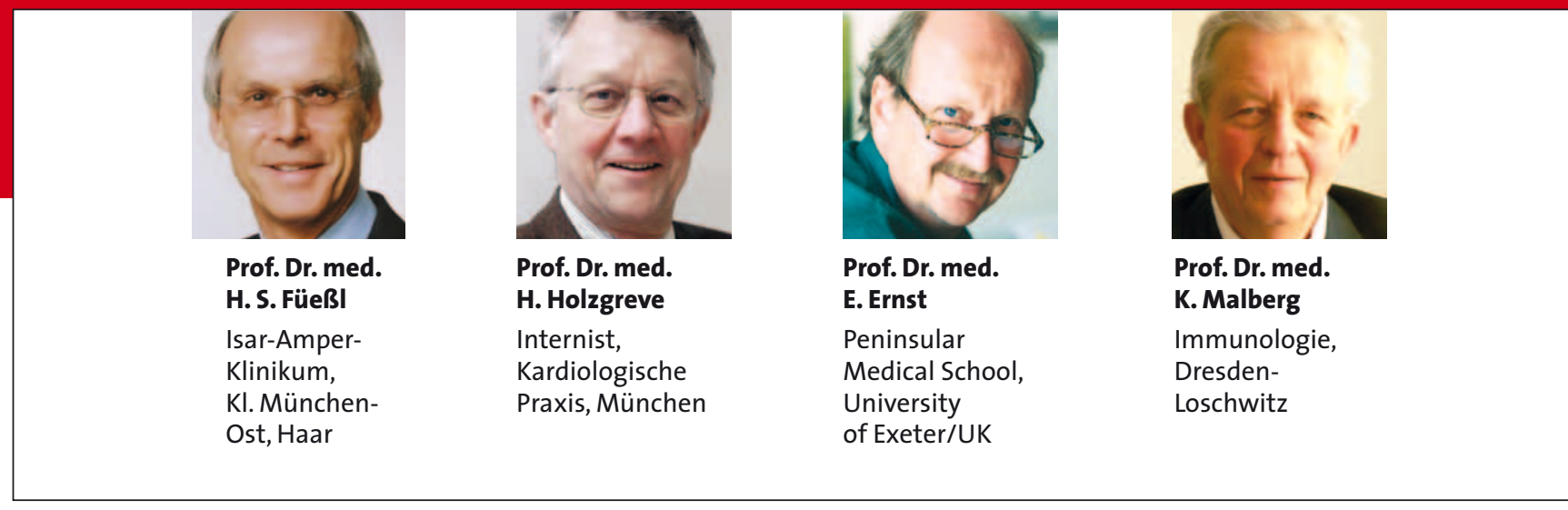

\section{Mammakarzinome durch Hormontherapie: modifizierte Kausalität}

\begin{abstract}
Nach der Publikation der Women's Health-Studie im Jahre 2002 wurden deutlich weniger Östrogene an Frauen in der Menopause verordnet. Gleichzeitig ging die Häufigkeit von Mammakarzinomen zunächst drastisch zurück, nahm dann aber wieder leicht zu.
\end{abstract}

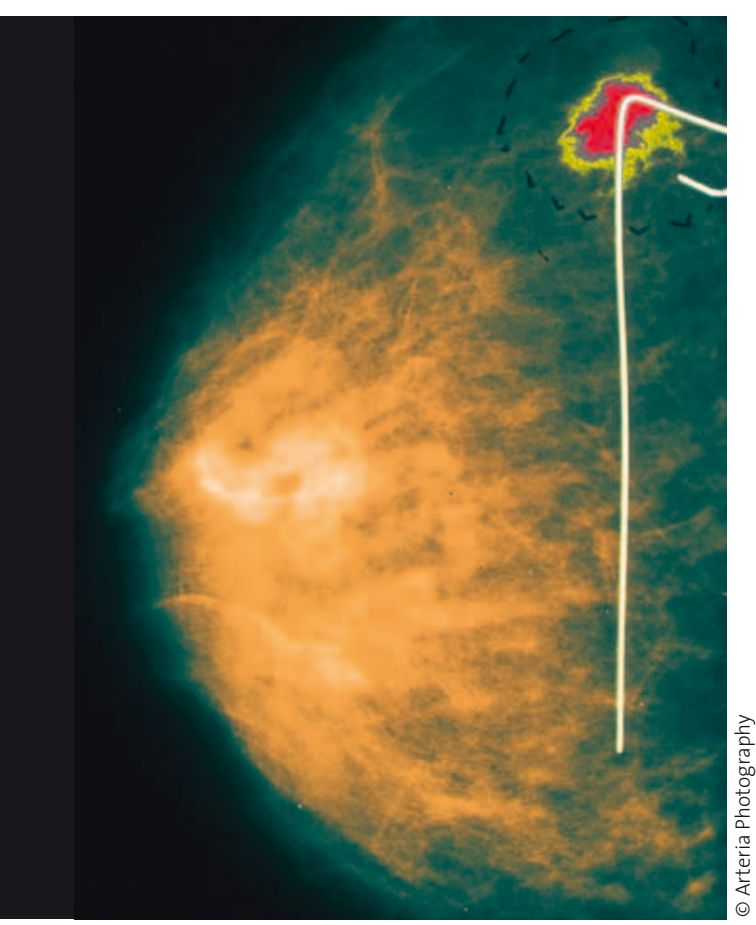

- Aus dem nationalen, kanadischen Register konnten die Autoren die Zahl der Hormonverordnungen für 50 bis 69 Jahre alte Frauen zwischen Anfang 2001 und Ende 2006 entnehmen. Der stärkste Abfall der Verordnungen für Östrogene und Progesteron allein und kombiniert setzte nach der Publikation der Women's Health-Studie 2002 ein.

Während Anfang 2002 noch 12,7\% aller Frauen im Alter zwischen 50 und 69 Jahren Hormone erhielten, waren es Ende 2004 nur noch 4,9\%. Gleichzeitig ging die Häufigkeit von Mammakarzinomen von 296,3 auf 268,0 pro 100000 Frauen, also um 9,6\%, zurück. Die Häufigkeit von Mammografien blieb in diesem Zeitraum mit $72 \%$ konstant.

Nach 2004 stagnierten die Hormonverordnungen bei etwa 5\%, während ab 2005 die Häufigkeit von Mammakarzinomen in allen Altersgruppen mit Ausnahme der 40-49-Jährigen wieder leicht anstieg.

4 Nach dem Rückgang der Hormonersatztherapie ging zunächst auch die Inzidenz der Mammakarzinome zurück.

\section{Kommentar}

Die Women's Health-Studie hatte 2002 gezeigt, dass die Hormonersatztherapie in der Menopause das Risiko für Schlaganfälle, Herzinfarkte und Mammakarzinome erhöht. Der zeitliche Zusammenhang zwischen dem Rückgang der Hormonverordnungen und der MammakarzinomInzidenz bestätigt die Ergebnisse der Women's Health-Studie. Auch in mehreren anderen Ländern wurde eine derartige Korrelation beschrieben.

Die Autoren vertreten die These, dass die Hormone nicht etwa Mammakarzinome verursachen, sondern das Wachstum hormonsensitiver Tumoren beschleunigen. Diese Vermutung vermag zu erklären, warum es nach einem Rückgang der Hormonverordnungen zunächst zu einem drastischen Rückgang der Mammakarzinome, mit einer gewissen Latenz dann aber zu einem leichten Reboundeffekt kommt.

H. Holzgreve •

- P. De et al.

Breast cancer incidence and hormone replacement therapy in Canada. J. Natl. Cancer Inst. 102 (2010) 1-7 